\title{
Técnicas de citologia aspirativa, biópsia e citobloco de medula óssea para identificação e determinação de intensidade parasitária na leishmaniose visceral canina
}

\author{
[Techniques of aspiration cytology, biopsy and cell block of the bone marrow for the identification \\ and determination of parasite intensity in Canine Visceral Leishmaniasis] \\ T.R. Antunes, K.C.S. Godoy, G.G. Oliveira, A.W. Silveira, C.A.N.R. Ramos, A.I. Souza \\ Fundação Universidade Federal de Mato Grosso do Sul - Campo Grande, MS
}

\begin{abstract}
RESUMO
O objetivo com este estudo foi comparar as técnicas de citologia aspirativa, biópsia e citobloco para identificação e quantificação parasitológica de Leishmania (Leishmania) infantum chagasi em medula óssea de cães. Amostras de tecido medular de 26 animais, em diferentes estágios clínico-laboratoriais da doença, foram estudadas obedecendo-se os mesmos critérios de investigação nas técnicas de citologia aspirativa, biópsia e citobloco. O menor número de campos para a confirmação parasitológica foi constatado no esfregaço direto obtido por citologia aspirativa. O estágio clínico-laboratorial não influenciou no número de campos necessários para a primeira visualização do agente em nenhuma das técnicas ( $>0,05)$, e menor intensidade parasitária foi observada nas lâminas de citobloco. As técnicas de citologia aspirativa e biópsia concordaram na estimativa do coeficiente de infectividade no tecido estudado $(p<0,05)$. Apesar de a técnica de citobloco permitir a concentração de células e o melhor reaproveitamento de amostras, não demonstrou ser um método adequado para rápida identificação e quantificação parasitológica na leishmaniose visceral canina. Considerando-se suas vantagens, a citologia aspirativa foi o melhor método para detecção microscópica do parasito e determinação do nível de intensidade parasitária no tecido estudado.
\end{abstract}

Palavras-chave: cão, diagnóstico parasitológico, Leishmania

\begin{abstract}
The aim of the present study was to compare the aspiration cytology, biopsy and cell block techniques for identification and parasitological quantification of Leishmania (Leishmania) infantum chagasi in dog bone marrow. Bone marrow tissue samples from 26 animals, in different clinical-laboratory stages of the disease, were studied according to the same criteria of investigation in the aspiration cytology, biopsy and cell block techniques. The lowest number of fields for the parasitological confirmation was found in the direct smear obtained by aspiration cytology. The clinical-laboratory stage did not influence the number of fields required for the first visualization of the agent in any of the techniques $(p>0.05)$ and less parasitic intensity was observed in the cell block slides. The aspiration cytology and biopsy techniques agreed on the estimation of infectivity coefficient in the tissue studied ( $p<0.05$ ). Although the cell block technique allows the concentration of cells and better reutilization of samples, it has not been shown to be an adequate method for rapid identification and parasitological quantification in canine visceral leishmaniasis. Considering its advantages, aspiration cytology was the best method for microscopic detection of the parasite and determination of the level of parasite intensity in the tissue studied.
\end{abstract}

Keywords: dog, parasitological diagnosis, Leishmania

Recebido em 8 de março de 2017

Aceito em 22 de novembro de 2017

E-mail: tamires_ramborger_antunes@hotmail.com 


\section{INTRODUÇÃO}

A leishmaniose visceral (LV) é uma doença endêmica, causada por protozoários do gênero Leishmania, que acometem mamíferos, inclusive o homem. Sua epidemiologia é complexa, com variações tanto no ciclo de transmissão como nos hospedeiros reservatórios, nos vetores e nas manifestações clínicas. Diferentes espécies de Leishmania circulam em uma mesma área geográfica e a Leishmania (Leishmania) infantum chagasi é considerada o principal agente da LV no Brasil, destacando-se os caninos domésticos como reservatórios urbanos da enfermidade (Solano-Gallego et al., 2011; Brasil, 2014).

Devido à inespecificidade dos sinais clínicos da doença, tanto nos seres humanos quanto nos animais, o diagnóstico da LV constitui muitas vezes um desafio (Gontijo e Melo, 2004; Silva et al., 2006; Brasil, 2014). O método parasitológico ainda é o meio mais específico para a detecção do agente, porém de sensibilidade variável, uma vez que depende da intensidade parasitária, do tipo de material biológico examinado e do número de campos observados ao microscópio (Giudice e Passantino, 2011; Solano-Gallego et al., 2011; Brasil, 2014).

A avaliação do tecido medular pode ser considerada ideal para a busca do agente e o monitoramento do tratamento. Estudo demonstrou que a medula óssea apresenta parasitismo persistente e sofre rápido acúmulo de amastigotas (Cotterell et al., 2000), além de ser um sítio de coleta mais seguro por oferecer menor risco de ocorrência de hemorragias quando comparado à aspiração esplênica (Brasil, 2014; Georgiadou et al., 2015).

Apesar de apresentar alta especificidade, a análise parasitológica é exaustiva e demorada. A avaliação de 1.000 campos, em objetiva de grande aumento, de amostras obtidas por meio de aspiração esplênica foi descrita por Chulay e Bryceson (1983) e tem sido aplicada até hoje (Ciaramella et al., 1997; Cardoso, 2010; Salam et al., 2012; Sundar et al., 2015). Assim, a investigação de métodos que possam otimizar a detecção e o acompanhamento clínicolaboratorial, utilizando-se o tecido medular, em diferentes estágios da LVC, é de grande importância.
Portanto, o objetivo com este estudo foi comparar as técnicas de citologia aspirativa, biópsia e citobloco para identificação e quantificação parasitológica de Leishmania (Leishmania) infantum chagasi em amostras de medula óssea de cães.

\section{MATERIAL E MÉTODOS}

O estudo foi aprovado pela Comissão de Ética no Uso de Animais da Fundação Universidade Federal de Mato Grosso do Sul (Ceua/UFMS), sob o protocolo de número 669/2015.

Foram utilizados 26 cães, sem restrição de sexo, raça, idade e peso corporal, que apresentaram formas amastigotas de Leishmania sp. no exame parasitológico de linfonodo. A reação em cadeia da polimerase (PCR), realizada conforme o protocolo descrito por Cortes et al. (2004), confirmou a presença e identificação da espécie Leishmania (L.) infantum chagasi no tecido medular.

Com base na avaliação dos sinais clínicos e em dados laboratoriais, os animais foram agrupados, utilizando-se adaptação da classificação de Solano-Gallego et al. (2011), em: estágio 1 ou doença leve (sinais clínicos leves, como linfadenomegalia periférica ou dermatite papular com ausência de alterações laboratoriais); estágio 2 ou doença moderada (sinais clínicos do estágio 1, além de lesões cutâneas simétricas ou difusas, onicogrifose, anorexia, perda de peso, febre e epistaxe associadas a alterações laboratoriais, como anemia, hiperglobulinemia e hipoalbuminemia e perfil renal normal); estágio 3 ou doença grave (alterações laboratoriais e sinais clínicos dos estágios 1 e 2, além de sinais provenientes de lesões por imunocomplexos, tromboembolismo pulmonar, síndrome nefrótica e doença renal crônica por estadiamento do IRIS - International Renal Interest Society).

Em obediência à Portaria Interministerial número 1.426 , de 11 de julho de 2008, que dispõe sobre as normas técnicas para o combate às leishmanioses no país, e após consentimento livre e esclarecido dos proprietários, os animais foram eutanasiados de acordo com a Resolução 714/2002 do Conselho Federal de Medicina Veterinária. A coleta do material para a avaliação da medula óssea foi realizada imediatamente após a eutanásia. 
Em todos os cães, as amostras foram coletadas por punção do úmero proximal, com o auxílio de agulha pediátrica do tipo Jamshidi, seguindo-se os métodos preconizados por Grindem et al. (2009), em que foi padronizada a obtenção de $2 \mathrm{~mL}$ e aproximadamente $1,5 \mathrm{~cm}$ para volume e fragmento de tecido medular, respectivamente. As amostras obtidas por aspiração foram utilizadas para realização dos esfregaços diretos e confecção dos citoblocos.

Os esfregaços foram confeccionados de acordo com Grindem et al. (2009) e corados com corantes do tipo Romanowsky. Os citoblocos foram processados pelo método de gel de agarose (Grefte et al., 2008), e os fragmentos de biópsia de acordo com a técnica histopatológica de rotina (Gartner e Hiatt, 2007). Ambos foram corados com hematoxilina e eosina (HE).

Os mesmos critérios foram obedecidos na avaliação das lâminas obtidas por meio do uso das técnicas de citologia aspirativa, de biópsia e de citobloco. A análise das lâminas foi realizada em microscópio óptico, com campo de grande aumento (cga), em objetiva de imersão (100x). A intensidade parasitária das amostras foi classificada de acordo com a adaptação do protocolo descrito por Chulay e Bryceson (1983) em: grau 0 (zero), diante de ausência de amastigotas após observação de 1.000 campos; grau 1+, após identificação entre uma e 10 amastigotas em 1.000 campos; grau $2+$, entre uma e 10 amastigotas em 500 campos; grau 3+, entre uma e 10 amastigotas em 100 campos; grau 4+, entre uma e 10 amastigotas em 10 campos; grau 5+, entre uma e 10 amastigotas no primeiro campo de avaliação; grau 6+, entre 10 e 100 amastigotas no primeiro campo de avaliação; e grau 7+, quando mais de 100 amastigotas foram visualizadas no primeiro campo de avaliação.

O número de campos examinados para detecção da primeira forma amastigota do agente foi comparado entre as técnicas com o teste de Friedman. Para avaliar a concordância entre os métodos, aplicou-se o índice Kappa (k) simples, baseado nos critérios de Landis e Koch (1977). A comparação entre os grupos clínico-laboratoriais nas três técnicas estudadas, em relação ao número de campos percorridos para a primeira observação do agente, foi realizada com o teste de Kruskal-Wallis, seguido pelo teste Dunn, quando necessário. $\mathrm{O}$ teste de Friedman foi utilizado para comparar, entre as técnicas, os graus de intensidade parasitária. Para todas as análises, as diferenças foram consideradas significativas quando $\mathrm{p}<0,05$.

\section{RESULTADOS E DISCUSSÃO}

A alta especificidade do exame parasitológico e as características comportamentais do tecido medular, diante da infecção pelo agente da leishmaniose, fizeram com que a avaliação da medula óssea fosse utilizada para o diagnóstico definitivo e o monitoramento da doença (Cotterell et al., 2000; Brasil, 2014; Georgiadou et al., 2015).

Rotineiramente, a avaliação microscópica e a confirmação da LV são realizadas mediante a observação do esfregaço coletado por punção aspirativa da medula óssea (Brasil, 2014). Além disso, a análise de amostras obtidas por biópsia do tecido medular vem sendo empregada (Kumar et al., 2007) e recentes estudos admitiram a utilização do citobloco como incremento à investigação (Abrantes et al., 2016; Menezes et $a l$., 2016), entretanto, ainda não foi estabelecido qual dos três métodos apresenta mais benefícios.

Ao realizar-se a busca do parasito em cada uma das técnicas, independentemente do estágio clínico-laboratorial da doença, foi possível observar que houve diferença no número de campos examinados para a identificação da primeira forma amastigota. $\mathrm{O}$ menor número de campos para a confirmação parasitológica e, consequentemente, a maior rapidez na determinação da positividade foi constatada no esfregaço direto (Fig. 1). Entretanto, quando as técnicas foram comparadas, não houve diferença estatística significativa entre citologia aspirativa e biópsia $(\mathrm{P}>0,05)$ (Fig. 1).

De acordo com o Ministério da Saúde (MS), uma amostra é considerada negativa após a análise de 200 campos microscópicos em objetiva de imersão (Brasil, 2014). Contudo, no presente trabalho, a aplicação desse critério acarretaria diagnósticos falso-negativos em 3,85\% (1/26) das amostras de esfregaço direto, $3,85 \%(1 / 26)$ de biópsia e 11,54\% (3/26) de citobloco (Fig. 1), corroborando as observações de Cardoso (2010). Os dados também demonstraram que a investigação em 1.000 campos, empregada por vários autores (Chulay e Bryceson, 1983; 
Ciaramella et al., 1997; Cardoso, 2010; Salam et al., 2012; Sundar et al., 2015), além de exaustiva, é desnecessária, já que o máximo de campos (476cga) para a visualização da primeira forma amastigota ocorreu na técnica de citobloco.

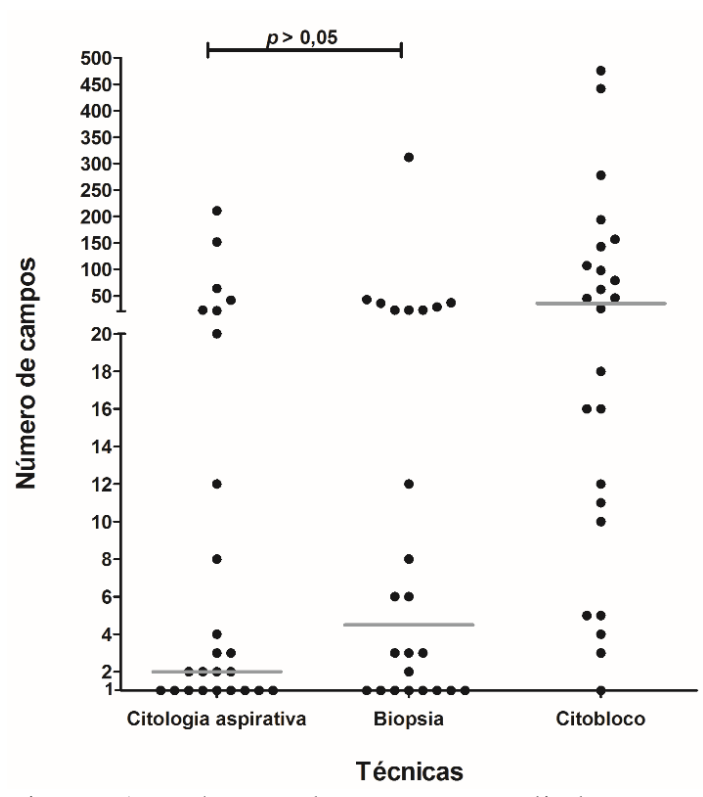

Figura 1. Número de campos avaliados para identificar a primeira forma amastigota de Leishmania (L.) infantum chagasi em tecido medular de cães. Os resultados são expressos de acordo com a mediana (barra cinza) e o número de campos analisados em cada técnica. A linha de bar na horizontal representa ausência de diferença estatística significativa pelo teste Friedman, no nível de 5\% de significância.

Independentemente do estágio clínicolaboratorial da doença, foi possível observar discordância entre os dados obtidos por meio da citologia aspirativa com as outras técnicas investigadas $(\mathrm{P}>0,05)$ e concordância moderada (Kappa $=0,4583 ; \quad \mathrm{P}<0,05)$ entre biópsia e citobloco. Esses resultados podem estar associados à frequência de falso-negativos na biópsia $(7,69 \%)$ e citobloco $(7,69 \%)$.

$\mathrm{Na}$ classificação clínico-laboratorial, 30,77\% $(8 / 26)$ dos cães apresentaram doença leve, $38,46 \%$ (10/26) moderada, e $30,77 \% \quad(8 / 26)$ grave. Diferença estatística significativa não foi constatada $(\mathrm{P}>0,05)$ ao se compararem esses grupos, em cada uma das técnicas, em relação ao número de campos percorridos, o que indica que o estágio da enfermidade não influenciou na primeira visualização do agente (Tab. 1).

Nas amostras dos animais no estágio 1, não foi observada diferença estatística significativa $(\mathrm{P}>0,05)$ ao se comparar, entre as técnicas, o número de campos percorridos para confirmação parasitológica. Nos estágios 2 e 3, o número de campos visualizados no esfregaço direto e nas lâminas confeccionadas por meio da biópsia foi inferior quando comparado ao citobloco (Tab. 1).

Estudo comparando citologia aspirativa e biópsia da medula óssea, para identificação de diferentes enfermidades infecciosas e não infecciosas, demonstrou que ambas as técnicas executadas na mesma área podem acarretar hipocelularidade local e promover discrepância diagnóstica entre esses métodos (Toi et al., 2010). Contudo, no presente trabalho, a ausência de diferença estatística entre essas técnicas $(\mathrm{P}>0,05)$ indicou que o mesmo sítio de coleta não interferiu no diagnóstico parasitológico. A variabilidade observada entre o número de campos percorridos para a primeira identificação do agente pode estar associada à heterogeneidade do tecido medular na LVC (Gontijo e Melo, 2004; Honse, 2014).

A técnica do citobloco, embora tenha ratificado a positividade, exigiu maior número de campos para a primeira identificação do agente (Tab. 1), e formas amastigotas extracelulares não foram observadas durante a leitura das lâminas. Na confecção do citobloco, a amostra é centrifugada e apenas o pellet é processado para análise (Ong et al., 2015; Abrantes et al., 2016), o que pode ter provocado descarte de amastigotas livres presentes no sobrenadante e justificar a obrigatoriedade de maior número de campos para a confirmação de LVC. Menezes et al. (2016) admitiram a necessidade de estudos complementares para o emprego dessa técnica como meio de triagem epidemiológica de rotina na doença. 
Tabela 1. Mediana e quartis do número de campos examinados, em diferentes técnicas de avaliação da medula óssea, para detecção parasitológica da primeira forma amastigota de Leishmania (L.) infantum chagasi em cães, de acordo com os diferentes estágios clínico-laboratoriais

\begin{tabular}{cccc}
\multirow{2}{*}{ Grupos } & \multicolumn{3}{c}{ Técnicas } \\
\cline { 2 - 4 } & Citologia aspirativa & Biópsia & Citobloco \\
\cline { 2 - 4 } & ${\mathrm{Md}\left(1^{\circ} \mathrm{Q} ; 3^{\circ} \mathrm{Q}\right)}_{2^{\mathrm{Aa}}(1 ; 7)}^{\left.\mathrm{Md} Q ; 3^{\circ} \mathrm{Q}\right)}$ & $\mathrm{Md}\left(1^{\circ} \mathrm{Q} ; 3^{\circ} \mathrm{Q}\right)$ \\
\hline Estágio 1 & $4^{\mathrm{Aa}}(2 ; 17)$ & $15^{\mathrm{Aa}}(3 ; 37)$ & $63^{\mathrm{Aa}}(10 ; 191)$ \\
Estágio 2 & $3^{\mathrm{ABa}}(1 ; 23)$ & $16^{\mathrm{Ba}}(9 ; 44)$ \\
Estágio 3 & $2^{\mathrm{ABa}}(1 ; 28)$ & $2^{\mathrm{Aa}}(1 ; 8)$ & $54^{\mathrm{Ba}}(17 ; 147)$ \\
\hline
\end{tabular}

Abreviações: Md: mediana; $1^{\circ} \mathrm{Q}$ : primeiro quartil; $2^{\circ} \mathrm{Q}$ : segundo quartil. Medianas seguidas de letras maiúsculas diferentes nas linhas diferem estatisticamente pelo teste de Friedman $(\mathrm{P}<0,05)$, e medianas seguidas das mesmas letras minúsculas nas colunas não diferem estatisticamente pelo teste de Kruskal-Wallis ( $\mathrm{P}>0,05)$.

A determinação da intensidade parasitária por microscopia óptica é considerada um método barato e confiável, que pode ser utilizada para avaliar o grau da resposta do paciente ao tratamento e determinar a correlação entre infectividade e alterações clínico-laboratoriais (Chulay e Bryceson, 1983; Cardoso, 2010; Singh et al., 2010). Reis et al. (2006) destacaram a utilização da quantificação parasitológica na medula óssea como um marcador auxiliar confiável na investigação do estágio clínicoinfeccioso na LVC.

No presente estudo, independentemente do estágio clínico-laboratorial da doença, observouse menor intensidade parasitária nas lâminas de citobloco (Fig. 2). Os efeitos causados pelo processamento do material, como apontado anteriormente, podem ter subestimado esses valores.

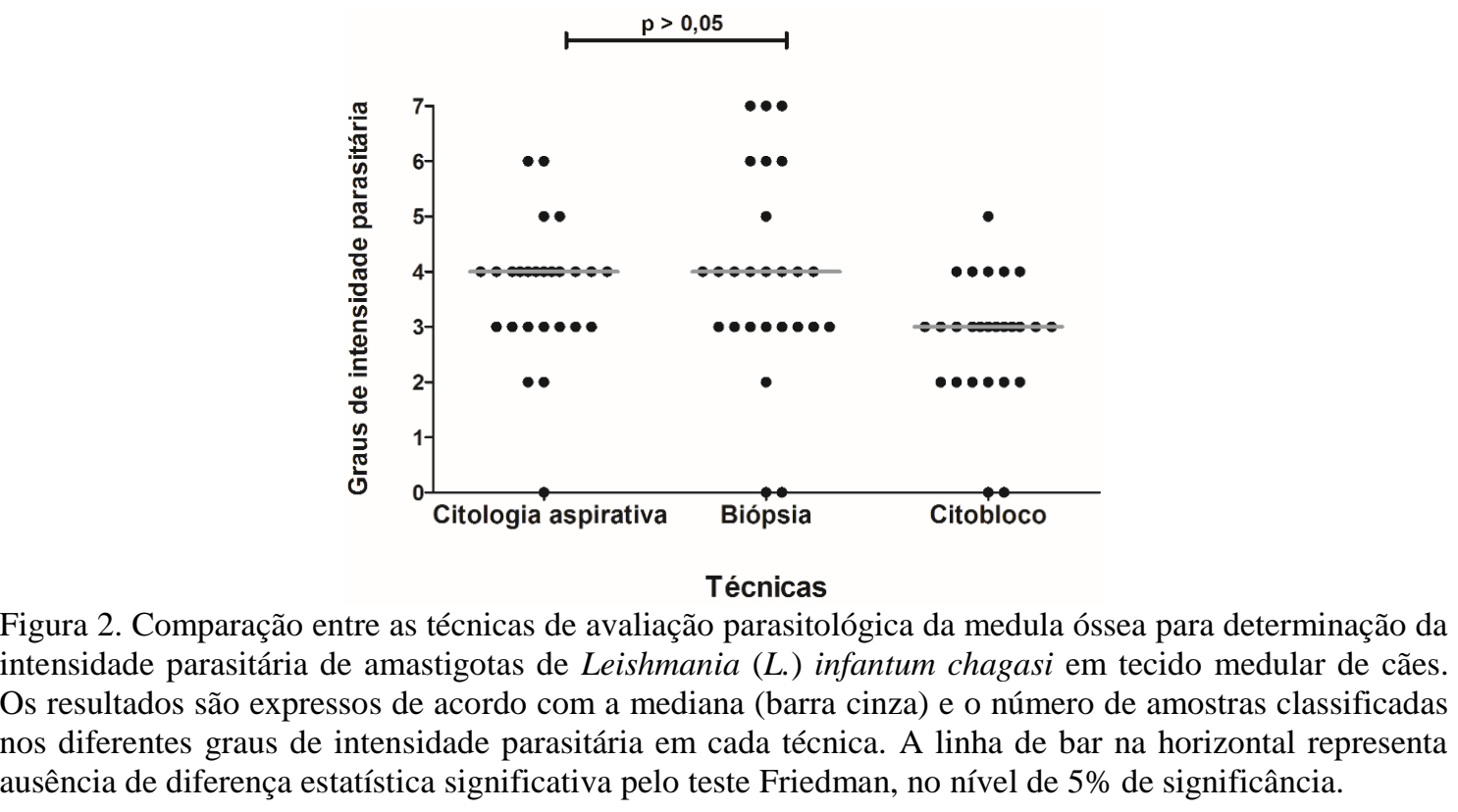

Figura 2. Comparação entre as técnicas de avaliação parasitológica da medula óssea para determinação da intensidade parasitária de amastigotas de Leishmania (L.) infantum chagasi em tecido medular de cães. Os resultados são expressos de acordo com a mediana (barra cinza) e o número de amostras classificadas nos diferentes graus de intensidade parasitária em cada técnica. A linha de bar na horizontal representa ausência de diferença estatística significativa pelo teste Friedman, no nível de 5\% de significância.
Após a investigação de 1.000 campos, foi possível classificar em grau zero $3,85 \%(1 / 26)$ dos esfregaços diretos, 7,69\% (2/26) das biópsias e $7,69 \%(2 / 26)$ dos citoblocos (Fig. 2), corroborando a capacidade diagnóstica da investigação no esfregaço direto. Em relação à estratificação em diferentes graus de parasitismo, não houve diferença estatística $(\mathrm{P}>0,05)$ entre amostras obtidas por citologia aspirativa e biópsia (Fig. 2), indicando que ambas as técnicas concordaram na estimativa do coeficiente de infectividade no tecido estudado. Entretanto, cabe destacar a facilidade de obtenção, processamento e custo da técnica de citologia aspirativa (Grindem et al., 2009). Contudo, ressalta-se a necessidade de estudos que permitam a validação desse teste em relação à quantificação parasitária na medula óssea. 


\section{CONCLUSÕES}

Apesar de a técnica de citobloco permitir a concentração de células e melhor reaproveitamento de amostras, esse método não demonstrou ser adequado para identificação rápida e quantificação parasitológica na LVC. Considerando suas vantagens, a citologia aspirativa foi a melhor técnica para detecção microscópica do parasito e determinação do nível de intensidade parasitária no tecido estudado.

\section{AGRADECIMENTOS}

À Fundação de Apoio ao Desenvolvimento do Ensino, Ciência e Tecnologia do Estado de Mato Grosso do Sul (Fundect), pela bolsa de estudo concedida (Fundect/Capes no 05/2015).

\section{REFERÊNCIAS}

ABRANTES, T.R.; MADEIRA, M.F.; SILVA, D.A. et al. Identification of canine visceral leishmaniasis in a previously unaffected area by conventional diagnostic techniques and cellblock fixation. Rev. Inst. Med. Trop. São Paulo, v.58, p.1-5, 2016.

BRASIL. Ministério da Saúde. Secretaria de Vigilância em Saúde. Departamento de Vigilância Epidemiológica. Manual de vigilância e controle da leishmaniose visceral. Brasília: Ministério da Saúde, 2014. 120p. (Série A. Normas e Manuais Técnicos)

CARDOSO, A.I.Q. Densidade parasitária em medula óssea de crianças com Leishmaniose Visceral e sua relação com os aspectos clínicos, laboratoriais e do tratamento. 2010. 61f. Dissertação (Mestrado em Doenças Infecciosas e Parasitárias) - Faculdade de Medicina, Universidade Federal de Mato Grosso do Sul, Campo Grande, MS.

CHULAY, J.D.; BRYCESON, A.D.M. Quantification of amastigotes of Leishmania donovani in smears of splenic aspirates from patients with visceral leshmaniasis. Am. J. Trop. Med. Hyg., v.32, p.475-479, 1983.

CIARAMELLA, P.; OLIVA, G.; LUNA, R. et al. A retrospective clinical study of canine leishmaniasis in 150 dogs naturally infected by Leishmania infantum. Vet. Rec., v.141, p.539343, 1997.
CORTES, S.; ROLÃO, N.; RAMADA, J.; CAMPINO, L. PCR as a rapid and sensitive tool in the diagnosis of human and canine leishmaniasis using Leishmania donovani s.l.specific kinetoplastid primers. Trans. R. Soc. Trop. Med. Hyg., v.98, p.12-17, 2004.

COTTERELL, S.E.; ENGWERDA, C.R.; KAYE, P.M. Leishmania donovani infection of bone marrow stromal macrophages selectively enhances myelopoiesis, by a mechanism involving GM-CSF and TNF-alpha. Blood, v.95, p.1642-1651, 2000.

GARTNER, L.P.; HIATT, J.L. Tratado de histologia em cores. 3.ed. Rio de Janeiro: Elsevier, 2007. 592p.

GEORGIADOU, S.P.; MAKARITSIS, K.P.; DALEKOS, G.N. Leishmaniasis revisited: current aspects on epidemiology, diagnosis and treatment. J. Trans. Intern. Med., v.3, p.43-50, 2015.

GIUDICE, E.; PASSANTINO, A. Detection of Leishmania amastigotes in peripheral blood from four dogs - short communication. Acta Vet. Hung., v.59, p.205-213, 2011.

GONTIJO, C.M.F.; MELO, M.N. Leishmaniose visceral no Brasil: quadro atual, desafios e perspectivas. Rev. Bras. Epidemiol., v.7, p.338349, 2004.

GREFTE, J.M.M.; WILD, P.C.; SALET-VAN POL, M.R.J. et al. Improved identification of malignant cells in serous effusions using a small, robust panel of antibodies on paraffin-embedded cell suspensions. Acta Cytol., v.54, p.35-44, 2008.

GRINDEM, C.B.; TYLER, R.D.; COWELL, R.L. A medula óssea. In: COWELL, R.L.; TYLER, R.D.; MEINKOTH, J.H.; DENICOLA, D.B. Diagnóstico citológico e hematologia de cães e gatos. 3.ed. São Paulo: Med Vet, 2009. p.423-451.

HONSE, C.O. Avaliação citopatológica da medula óssea e perfil hematológico de cães naturalmente infectados por Leishmania (Leishmania) chagasi. 2014. 81f. Tese (Doutorado em Pesquisa Clínica em Doenças Infecciosas) - Instituto de Pesquisa Clínica Evandro Chagas, Rio de Janeiro, RJ. 
KUMAR, P.V.; VASEI, M.; SADEGHIPOUR, A. et al. Visceral leishmaniasis: bone marrow biopsy findings. J. Pediatr. Hematol. Oncol., v.29, p.77-80, 2007.

LANDIS, J.R.; KOCH, G.G. An application of hierarchical kappa-type statistics in the assessment of majority agreement among multiple observers. Biometrics, v.33, p.363-374, 1977.

MENEZES, R.C.; MADEIRA, M.F.; FERREIRA, L.C. Cell-block immunohistochemistry of bone marrow aspirates: a novel tool to improve the diagnosis of leishmania infection in dogs. J. Comp. Pathol., v.154, p.157-160, 2016.

ONG, M.G.; LOWERY-NORDBERG, M.; PILLARISETTI, S. et al. Maximizing the diagnostic yield from bone marrow aspirate material using the cell block technique on clot sections. Lab. Med., v.46, p.24-27, 2015.

REIS, A.B.; MARTINS-FILHO, O.A.; TEIXEIRA-CARVALHO, A. et al. Parasite density and impaired biochemical/hematological status are associated with severe clinical aspects of canine visceral leishmaniasis. Res. Vet. Sci., v.81, p.68-75, 2006.

SALAM, M.A.; KHAN, M.G.M.; BHASKAR, K.R.H. et al. Peripheral blood buffy coat smear: a promising tool for diagnosis of visceral leishmaniasis. J. Clin. Microbiol., v.50, p.837840, 2012.
SILVA, E.S.; VAN DER MEIDE, W.F.; SCHOONE, G.J. et al. Diagnosis of canine leishmaniasis in the endemic area of Belo Horizonte, Minas Gerais, Brazil by parasite, antibody and DNA detection assays. Vet. Res. Commun., v.30, p.637-643, 2006.

SINGH, U.K.; PRASAD, R.; JAISWAL, B.P. et al. Amphotericin B therapy in children with visceral leishmaniasis: daily vs. alternate day, a randomized trial. J. Trop. Pediatr., v.56, p.321324, 2010.

SOLANO-GALLEGO, L.; MIRÓ, G.; KOUTINAS, A. et al. LeishVet guidelines for the practical management of canine leishmaniosis. Parasit. Vectors, v.4, p.1-16, 2011.

SUNDAR, S.; SINGH, A.; RAI, M.; CHAKRAVARTY, J. Single-dose indigenous liposomal amphotericin B in the treatment of Indian visceral leishmaniasis: a phase 2 study. Am. J. Trop. Med. Hyg., v.92, p.513-517, 2015.

TOI, P.C.; VARGHESE, R.B.; RAI, R. Comparative evaluation of simultaneous bone marrow aspiration and bone marrow biopsy: an institutional experience. Indian J. Hematol. Blood Transfus., v.26, p.41-44, 2010. 